\title{
Augmented reality practices in health services: Literature review
}

\author{
Merve Boşat a,* (iD , Emrah Önder b (iD) , Uğur Arcagök ${ }^{c}$ (iD) \\ a Bezmialem Vakıf University, Faculty of Health Sciences, TR-34050, Istanbul Turkey \\ b Doç. Dr, İstanbul University, School of Business, TR-34322, Istanbul Turkey \\ c Muş Alparslan University, School of Economics and Administrative Sciences, TR-49120, Istanbul Turkey
}

\section{A R T I C L E INFO}

\section{Article history:}

Received 27 October 2020

Received in revised form 00 January 0000

Accepted 21 December 2020

\section{Keywords:}

Augmented Reality

Health

Health Services

\begin{abstract}
AB S T R ACT
Augmented reality (AR) is a version of virtual reality (VR) technology, and digital three-dimensional interfaces and virtual objects appear before us as a dynamic and innovative technology allowing simultaneous interaction with the real world. Today, we encounter wearable technologies as the widespread use of augmented reality technologies. Along with the rapid proliferation of mobile devices and wireless network technologies, innovative technologies such as augmented reality (AR) and virtual reality (VR) have also become useable in each domain. The development of health technologies also in the same pace brings along the opportunities for using such technologies in the domain of health. In the present study, literature review on AR practices used in the domain of health was made, and the data was analyzed.
\end{abstract}

(C) 2020. Turkish Journal Park Academic. All rights reserved.

\section{Introduction}

Milgram and Kishino (1994) had defined augmented reality as "the environment of reality in which the products of digital media are being used instead of the objects of the real world". Augmented reality (AR) is a version of virtual reality (VR) technology, and digital three-dimensional interfaces and virtual objects appear before us as a dynamic and innovative technology allowing simultaneous interaction with the real world (Azuma, 1997; Sommerauer and Müller, 2014). When the definitions in literature are reviewed, augmented reality may be defined as real worlds that are enriched with the use of virtual objects According to this, augmented reality is an environment that consists of real and virtual objects formed by virtual objects placed in the real-world environment with experiential purposes. Today, we encounter wearable technologies as the widespread use of augmented reality technologies. In this manner, the co-occurrence of virtual objects and real beings ensures the increase of sense of reality in the users of augmented reality (Bokyung, 2008). Along with the rapid proliferation of mobile devices and wireless network technologies, innovative technologies such as augmented reality (AR) and virtual reality (VR) have also become useable in each domain. The development of health technologies also in the same pace brings along the opportunities for using such technologies in the domain of health.

When AR practices' usage area in the domain of health is considered, they are being used in order to easily determine the point of interference in surgical operations, and in order to minimize the risk of infection by making smaller cuts on the patient. In the domain of neurosurgery, it was observed that it

\footnotetext{
* This study was presented as an oral presentation at the Anatolian International Multidisciplinary Studies Congress held in Diyarbakır on 28-29 December 2018.

* Corresponding author.

E-mail address: u.arcagok@alparslan.edu.tr,

ORCID : 0000-0002-8465-9907
} 
is being used for accessing the area of tumor, decreasing the size of cut, or displaying three dimensionally the construct of veins in brain in cases of aneurysm. And in the domain of physiotherapy and rehabilitation, it is encountered that it is being used both on adults and children with the purpose of having the patients perform the given movements in a correct manner along with the creation of the perception of reality. Lastly, the domain that is frequently encountered is education. In medical education, especially in the domain of anatomy, it is observed that AR practices are being used, and thus that it is very useful in cases where training on cadaver cannot be made, or where the students want to study a subject again. In addition, we are also observing that it started to be used on the education of health habits such as getting the children adopting the habit of brushing their teeth.

\subsection{The purpose of the research}

The purpose of the present study is to determine AR practices' usage area in the domain of health. For this purpose, an extensive literature review was performed. Moreover, it is being considered to also reveal information on the states of the researchers performing such researches, the change of researches as per years, and the magazines where they were published. Along with the determination of the subjects on which it was concentrated the most in this field, it was intended to reveal the results that will shed light on the future researches.

\section{Method}

For an extensive literature review, EDS search engine, enabling access to all the subscribed databases from a single access point by the provider service of "EBSCO Discovery Services", was directly accessed through the website of the Library and Documentation Directorate of University of Bezmialem Foundation. The key words of "augmented reality" and "healthcare" were written in the search section, and in the content providers section, Complementary Index, Scopus $₫$, IEEE Xplore Digital Library, Newspaper Source Plus, Academic Search Complete, Science Citation Index, Regional Business News, Business Source Complete, MasterFILE Complete, Networked Digital Library of Theses \& Dissertations, MEDLINE, MEDLINE Complete, General OneFile, Supplemental Index, Directory of Open Access Journals, ScienceDirect, Social Sciences Citation Index, Newswires, CINAHL Complete, arXiv, ERIC, Library \& Information Science Source, Library, Information Science \& Technology Abstracts, Food Science Source, Journals@OVID, Arts \& Humanities Citation Index, Teacher Reference Center, DergiPark, China Science \& Technology Journal Database, Emerald Insight, National Database of ULAKBIM (Turkish Academic Network and Information Center), Dentistry \& Oral Sciences Source, eBook Academic Collection Trial, JSTOR Journals, GreenFILE, Research Starters, Books at JSTOR, Dynamed, Bibliotheksverbund Bayern, eBook Index, Google Scholar, and ProQuest Dissertation and Thesis database were selected.
The conformity to key words of the listed articles was examined again, and 46 publications in total were obtained. Each of the reviewed publications were listed with the used of MS Excel program in the direction of the intended objectives, and the obtained data was analyzed.

\section{Findings}

The distribution of the authors as per the states is listed as seen in Graph 1. According to the analysis performed, it is being observed that most of the researches on AR practices used in health services are originating from USA [16,19,22,42,44,45,]. And then Canada is following USA in terms of researches performed on the same $[18,20,24,43]$.

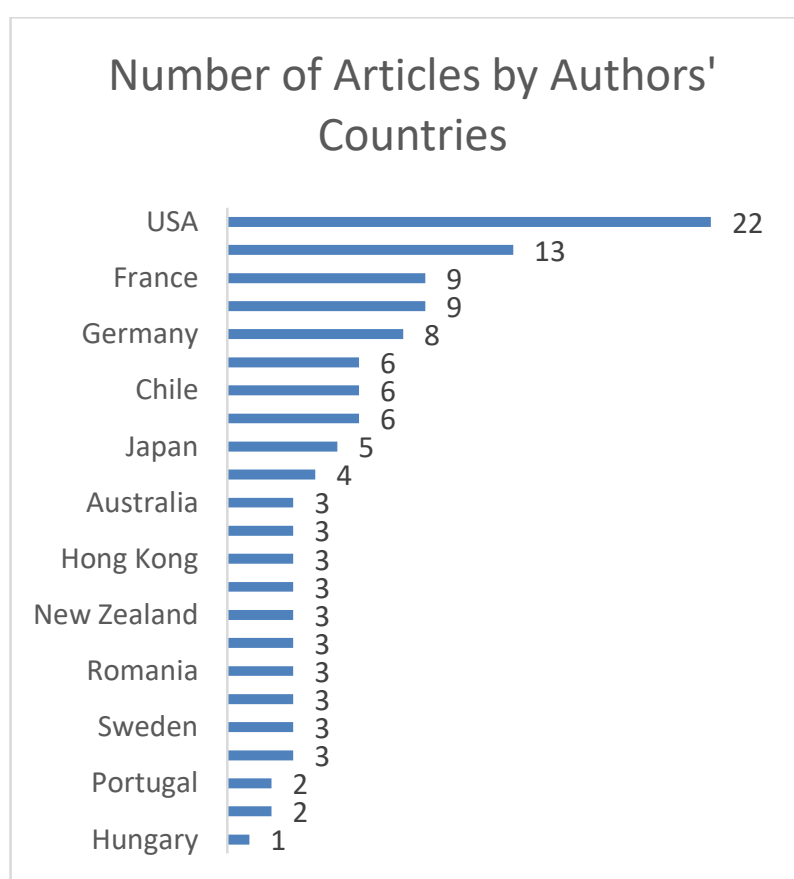

Figure 1. Distribution as per states of AR studies performed in the domain of health

And when the research methods used in the studies were examined, it was observed that literature review $[8,9,10,13,14,19,33,34,36,40]$, compilation and AR practices applied on surgical operations were published at a high degree $[17,18,20,24,26,35,44]$. (Graph 2) 


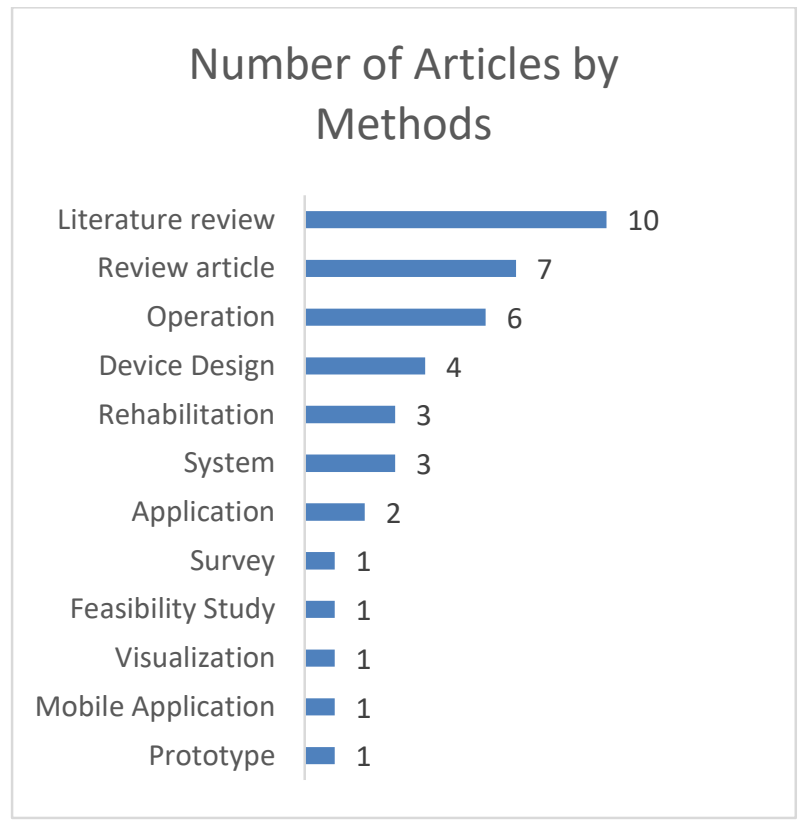

Figure 2. Methods used in the publications on AR practices used in the domain of health

When the fields of application of AR, used in trainings provided in the domain of health, were examined, it is being observed by Graph 3 that it was used the most in the medical education $[5,7,8,11,14,22,36,40,43]$.

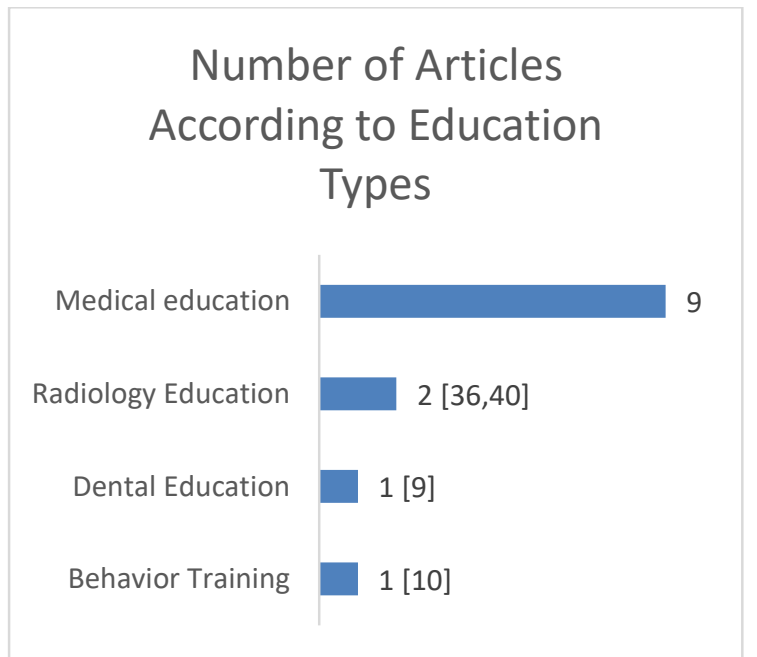

Figure 3. Types of health education provided by AR practices

When articles on AR practices used in surgical sciences were examined, it was observed that the highest number of publications was on the domain of General Surgery as clinical domain $[13,17,20,44]$.

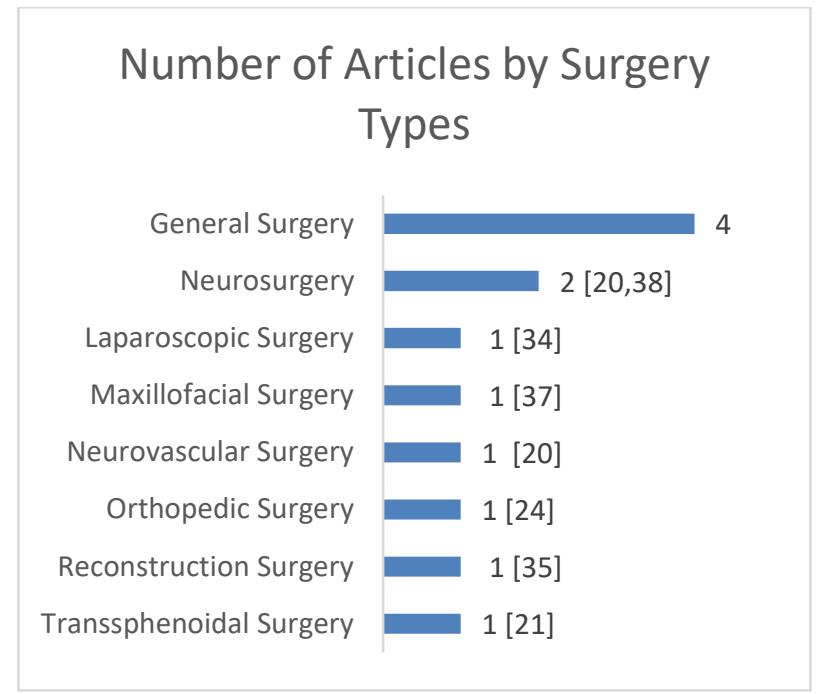

Figure 4. Use of AR practices in surgical branches

And when the key words of the publications were analyzed, it is being observed by Graph 5 that the most frequently used key word was "Augmented Reality" [5,7,8,9,11,13, $14,15,16,17,19,20,21,22,23,26,27,29,31,33,34,35,37,38,39,41$, $42,44,45,46]$, and the second one was "Virtual Reality" $[8,9,13$, $14,16,25,27,37,41]$.

\section{Most Frequently Used Keywords}

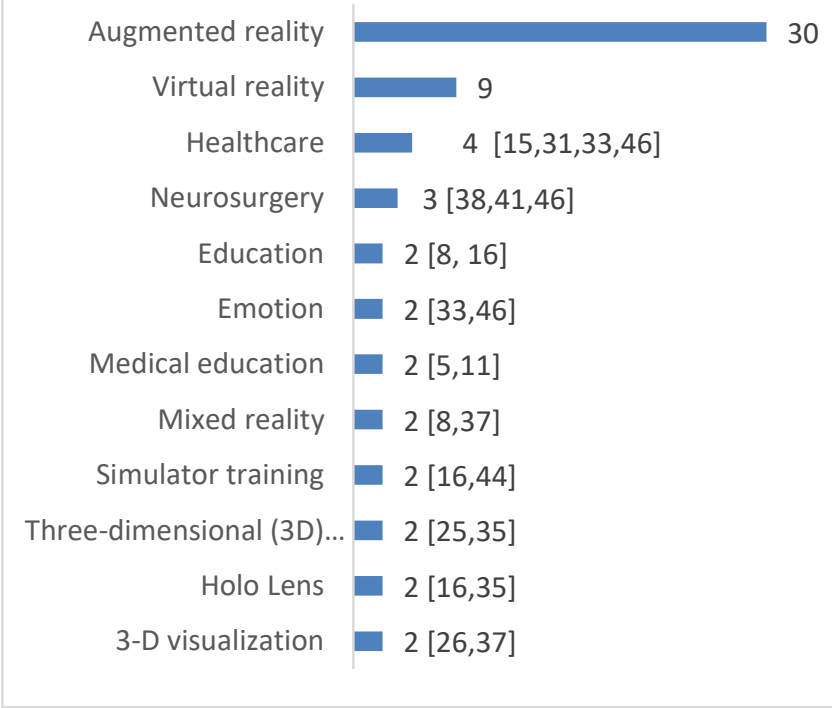

Figure 5. The most frequently used key words

And when number of articles was examined as per years, the highest leap had occurred in 2018 by 20 articles as seen on Graph 6. 


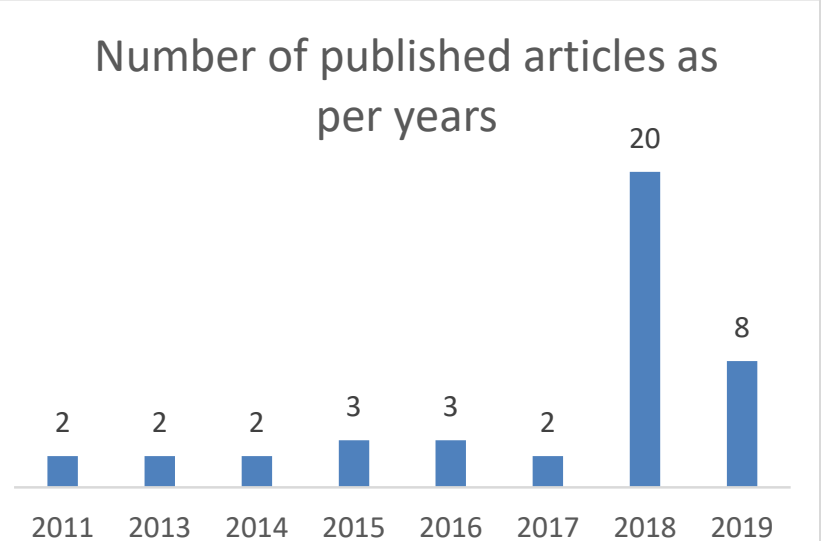

Figure 6. Number of published articles as per years

The following results were obtained by the analysis of journals on which the articles were published

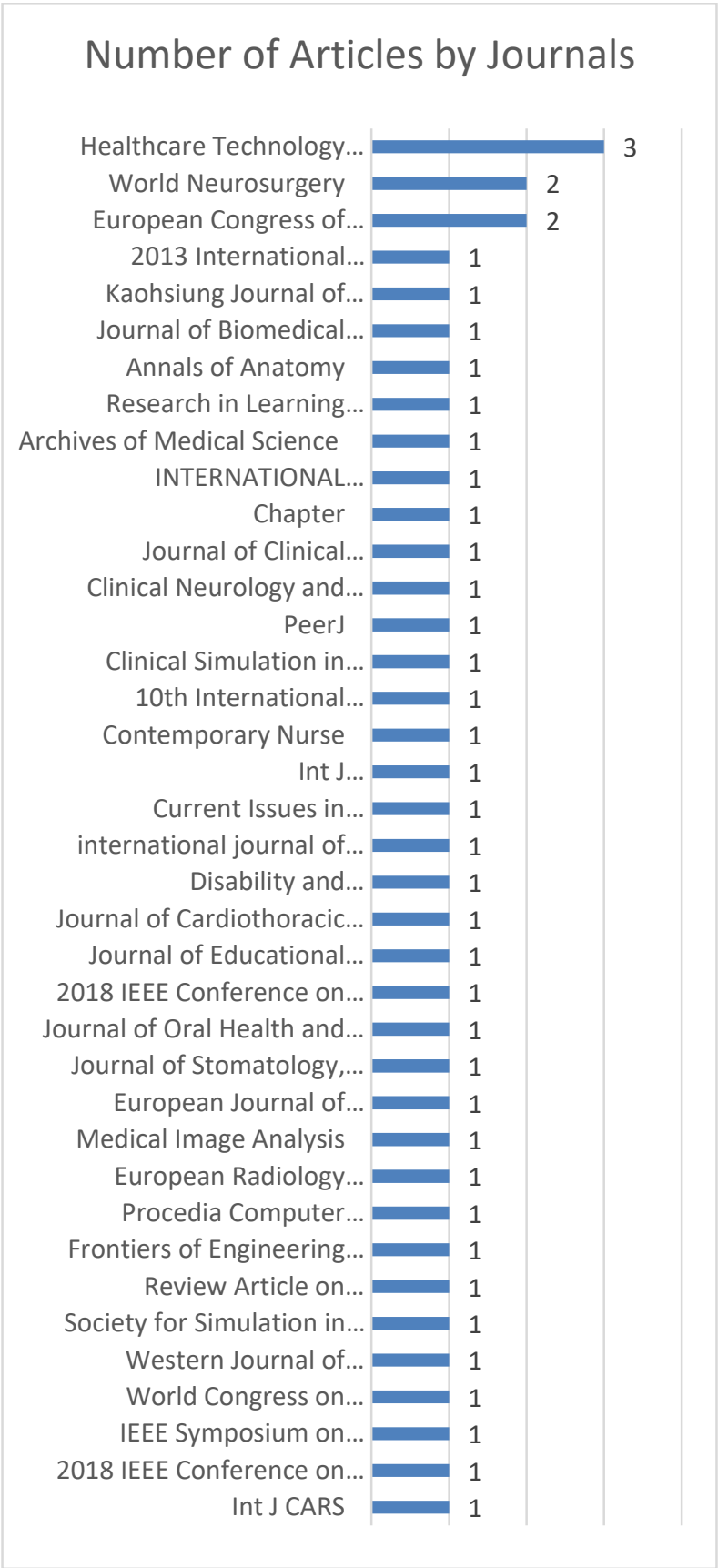

Figure 7. Number of articles by journals

\section{Conclusions}

According to the obtained results, we observe that AG practices had significantly increased as of year 2018. It will not be incorrect to say that ease of access to the referred services along with the development of AR systems had caused that increase. And along with the increase of malpractice actions in the whole world, it is a reality that the use of practices, that will minimize human error, will increase. It is being anticipated 
that this technology will be increasingly used both in the domain of clinics and in the domain of education.

\section{References}

1. Azuma, R. T. (1997). A survey of augmented reality. Presence: Teleoperators and virtual environments, 6(4), 355-385

2. Bokyung, K. (2008). Investigation on the relationships among media characteristics, presence, flow, and learning effects in augmented reality-based learning. Multimedia and E-Content Trends içinde (ss.. 21-37). Vieweg+ Teubner

3. Milgram, P., \& Kishino, F. (1994). A taxonomy of mixed reality visual displays. IEICE Transactions on Information Systems, 77 (12), 1321-1329.

4. Sommerauer, P. ve Müller, O. (2014). Augmented reality in informal learning environments: A field experiment in a mathematics exhibition. Computers \& Education, 79, 59-68.

5. Zhu, E., Hadadgar, A., Masiello, I., \& Zary, N. (2014). Augmented reality in healthcare education: an integrative review. PeerJ, 2, e469.

6. Ma, M., Jain, L. C., \& Anderson, P. (2014). Future trends of virtual, augmented reality, and games for health. In Virtual, augmented reality and serious games for healthcare $1 \mathrm{cpp}$ 1-6). Springer, Berlin, Heidelberg.

7. Layona, R., Yulianto, B., \& Tunardi, Y. (2018). Web based Augmented Reality for Human Body Anatomy Learning. Procedia Computer Science, 135, 457-464.

8. Yuen, S. C. Y., Yaoyuneyong, G., \& Johnson, E. (2011) Augmented reality: An overview and five directions for AR in education. Journal of Educational Technology Development and Exchange (JETDE), 4(1), 11

9. Dutã, M., Amariei, C. I., Bogdan, C. M., Popovici, D. M., Ionescu, N., \& Nuca, C. I. (2011). An overview of virtual and augmented reality in dental education. Oral Health Dent Manag, 10, 42-49.

10. Ferguson, C., Davidson, P. M., Scott, P. J., Jackson, D., \& Hickman, L. D. (2015). Augmented reality, virtual reality and gaming: An integral part of nursing.

11. Kugelmann, D., Stratmann, L., Nühlen, N., Bork, F., Hoffmann, S., Samarbarksh, G., ... \& Navab, N. (2018). An augmented reality magic mirror as additive teaching device for gross anatomy. Annals of Anatomy-Anatomischer Anzeiger, 215, 71-77.

12. Zhao, M. Y., Ong, S. K., \& Nee, A. Y. (2016). An augmented reality-assisted therapeutic healthcare exercise system based on bare-hand interaction. International Journal of Human-Computer Interaction, 32(9), 708-721.

13. Khor, W. S., Baker, B., Amin, K., Chan, A., Patel, K., \& Wong, J. (2016). Augmented and virtual reality in surgery-the digital surgical environment: applications, limitations and legal pitfalls. Annals of translational medicine, 4(23).

14. Huang, T. K., Yang, C. H., Hsieh, Y. H., Wang, J. C., \& Hung, C. C. (2018). Augmented reality (AR) and virtual reality (VR) applied in dentistry. The Kaohsiung journal of medical sciences, 34(4), 243-248.

15. Monge, J., \& Postolache, 0. (2018, October). Augmented reality and smart sensors for physical rehabilitation. In
2018 International Conference and Exposition on Electrical And Power Engineering (EPE) (pp. 1010-1014). IEEE.

16. Mahmood, F., Mahmood, E., Dorfman, R. G., Mitchell, J., Mahmood, F. U., Jones, S. B., \& Matyal, R. (2018). Augmented reality and ultrasound education: initial experience. Journal of cardiothoracic and vascular anesthesia, 32(3), 13631367.

17. Wang, Y. Y., Liu, H. P., Hsiao, F. L., \& Kumar, A. (2019) Augmented reality for temporomandibular joint arthrocentesis: a cadaver study. International journal of oral and maxillofacial surgery.

18. Vassallo, R., Kasuya, H., Lo, B. W., Peters, T., \& Xiao, Y. (2018). Augmented reality guidance in cerebrovascular surgery using microscopic video enhancement. Healthcare technology letters, 5(5), 158-161.

19. Tagaytayan, R., Kelemen, A., \& Sik-Lanyi, C. (2018) Augmented reality in neurosurgery. Archives of medical science: AMS, 14(3), 572.

20. Kersten-Oertel, M., Gerard, I., Drouin, S., Mok, K., Sirhan, D., Sinclair, D. S., \& Collins, D. L. (2015). Augmented reality in neurovascular surgery: feasibility and first uses in the operating room. International journal of computer assisted radiology and surgery, 10(11), 1823-1836.

21. Carl, B., Bopp, M., Voellger, B., Saß, B., \& Nimsky, C. (2019). Augmented Reality in Transsphenoidal Surgery. World neurosurgery.

22. Carlson, K. J., \& Gagnon, D. J. (2016). Augmented reality integrated simulation education in health care. Clinical simulation in nursing, 12(4), 123-127.

23. Kanno, K. M., Lamounier, E. A., Cardoso, A., Lopes, E. J., \& de Lima, G. F. M. (2018, March). Augmented Reality System for Aiding Mild Alzheimer Patients and Caregivers. In 2018 IEEE Conference on Virtual Reality and 3D User Interfaces (VR) (pp. 593-594). IEEE.

24. El-Hariri, H., Pandey, P., Hodgson, A. J., \& Garbi, R. (2018) Augmented reality visualisation for orthopaedic surgical guidance with pre-and intra-operative multimodal image data fusion. Healthcare Technology Letters, 5(5), 189-193.

25. Debarba, H. G., de Oliveira, M. E., Lädermann, A., Chagué, S. \& Charbonnier, C. (2018, March). Augmented reality visualization of joint movements for physical examination and rehabilitation. In 2018 IEEE Conference on Virtual Reality and 3D User Interfaces (VR) (pp. 537-538). IEEE.

26. Zhang, B., Ma, L., Qu, X., Zhang, X., \& Liao, H. (2019). Augmented-Reality Surgical Navigation System for Better Healthcare Visualization. In World Congress on Medical Physics and Biomedical Engineering 2018 (pp. 809-813). Springer, Singapore.

27. Ibrahim, Z., \& Money, A. G. (2019). Computer Mediated Reality Technologies: A Conceptual Framework and Survey of the State of the Art in Healthcare Intervention Systems. Journal of biomedical informatics, 103102.

28. Mewes, A., Heinrich, F., Hensen, B., Wacker, F., Lawonn, K., \& Hansen, C. (2018). Concepts for augmented reality visualisation to support needle guidance inside the MRI. Healthcare technology letters, 5(5), 172-176.

29. Séblain, D., Capitaine, A. G., \& Khonsari, R. H. (2019). Connected toothbrush, augmented reality and oral hygiene 
in children with cleft lip and palate. Journal of stomatology, oral and maxillofacial surgery, 120(1), 83.

30. Kobayashi, L., Zhang, X. C., Collins, S. A., Karim, N., \& Merck, D. L. (2018). Exploratory application of augmented reality/mixed reality devices for acute care procedure training. Western Journal of Emergency Medicine, 19(1), 158.

31. Basoglu, N. A., Goken, M., Dabic, M., Ozdemir Gungor, D., \& Daim, T. U. (2018). Exploring adoption of augmented reality smart glasses: Applications in the medical industry.

32. Stretton, T., Cochrane, T., \& Narayan, V. (2018). Exploring mobile mixed reality in healthcare higher education: a systematic review. Research in Learning Technology, 26, 2131-2131.

33. Tivatansakul, S., \& Ohkura, M. (2013, April). Healthcare system design focusing on emotional aspects using augmented reality-Relaxed service design. In 2013 IEEE Symposium on Computational Intelligence in Healthcare and e-health (CICARE)(pp. 88-93). IEEE.

34. Bernhardt, S., Nicolau, S. A., Soler, L., \& Doignon, C. (2017). The status of augmented reality in laparoscopic surgery as of 2016. Medical image analysis, 37, 66-90.

35. Pratt, P., Ives, M., Lawton, G., Simmons, J., Radev, N., Spyropoulou, L., \& Amiras, D. (2018). Through the HoloLens $^{\mathrm{TM}}$ looking glass: augmented reality for extremity reconstruction surgery using 3D vascular models with perforating vessels. European radiology experimental, 2(1), 2.

36. Tapia, M. F., Hasson, D., \& Labra, A. (2019). The prostate anatomy, a useful tool for clinical practice: assessed through augmented reality. Contacto Científico, 8(Especial A).

37. Bosc, R., Fitoussi, A., Hersant, B., Dao, T. H., \& Meningaud, J. P. (2018). Intraoperative augmented reality with heads-up displays in maxillofacial surgery: a systematic review of the literature and a classification of relevant technologies. International journal of oral and maxillofacial surgery.

38. López, W. O. C., Navarro, P. A., \& Crispin, S. (2018). Intraoperative clinical application of augmented reality in neurosurgery: A systematic review. Clinical neurology and neurosurgery.

39. Corrêa, A. G. D., de Assis, G. A., do Nascimento, M., \& de Deus Lopes, R. (2017). Perceptions of clinical utility of an Augmented Reality musical software among health care professionals. Disability and Rehabilitation: Assistive Technology, 12(3), 205-216.

40. Hasson, D. (2018, January). ITMIG classification of mediastinal anatomy: exposure through augmented reality. European Congress of Radiology 2018.

41. Lee, C., \& Wong, G. K. C. (2019). Virtual reality and augmented reality in the management of intracranial tumors: A review. Journal of Clinical Neuroscience.

42. Li, H., Gupta, A., Zhang, J., \& Flor, N. (2018). Who will use augmented reality? An integrated approach based on text analytics and field survey. European Journal of Operational Research

43. Garrett, B. M., Anthony, J., \& Jackson, C. (2018). Using mobile augmented reality to enhance health professional practice education. Current Issues in Emerging eLearning, 4(1), 10.

44. Andersen, D. S., Cabrera, M. E., Rojas-Muñoz, E. J., Popescu, V. S., Gonzalez, G. T., Mullis, B., ... \& Wachs, J. P. (2019). Augmented Reality Future Step Visualization for Robust Surgical Telementoring. Simulation in Healthcare, 14(1), 5966.

45. Karmonik, C., Elias, S. N., Zhang, J. Y., Diaz, O., Klucznik, R. P., Grossman, R. G., \& Britz, G. W. (2018). Augmented reality with virtual cerebral aneurysms: a feasibility study. World neurosurgery, 119, e617-e622.

46. Tivatansakul, S., \& Ohkura, M. (2013, July). Healthcare system focusing on emotional aspects using augmented reality-implementation of breathing control application in relaxation service. In 2013 International Conference on Biometrics and Kansei Engineering (pp. 218-222). IEEE. 